\author{
Marquette University \\ e-Publications@Marquette
}

$1-2014$

\title{
Where does Racial Discrimination Occur? An Experimental Analysis Across Neighborhood and Housing Unit Characteristics
}

Andrew Hanson

Marquette University, andrew.r.hanson@marquette.edu

Zackary Hawley

Texas Christian University

Follow this and additional works at: https://epublications.marquette.edu/econ_fac

Part of the Economics Commons

\section{Recommended Citation}

Hanson, Andrew and Hawley, Zackary, "Where does Racial Discrimination Occur? An Experimental Analysis Across Neighborhood and Housing Unit Characteristics" (2014). Economics Faculty Research and Publications. 405.

https://epublications.marquette.edu/econ_fac/405 
Marquette University

e-Publications@Marquette

\title{
Economics Faculty Research and Publications/College of Business Administration
}

This paper is NOT THE PUBLISHED VERSION; but the author's final, peer-reviewed manuscript. The published version may be accessed by following the link in the citation below.

Regional Science and Urban Economics, Vol. 44 (January 2014): 94-106. DOI. This article is (C) Elsevier and permission has been granted for this version to appear in e-Publications@Marquette. Elsevier does not grant permission for this article to be further copied/distributed or hosted elsewhere without the express permission from Elsevier.

\section{Where Does Racial Discrimination Occur? An Experimental Analysis Across Neighborhood and Housing Unit Characteristics}

\author{
Andrew Hanson \\ Department of Economics, Marquette University, Milwaukee, WI \\ Zackary Hawley \\ Department of Economics, Texas Christian University, Fort Worth, TX
}

\begin{abstract}
This paper examines racial discrimination across several neighborhood and housing unit characteristics including racial composition, rent, and distance from the urban core. We find that African Americans face higher rates of discrimination than whites in a wide range of racially mixed neighborhoods, in higher rent areas, closer to central cities, and in low vacancy areas. These results are robust to various parameterizations of the local smoothing empirical specification and within a multivariate nonlinear parametric estimation technique. The location of discrimination supports the current/future customer prejudice and perceived preference hypotheses as a cause of discrimination in housing markets but not the landlord taste-based hypothesis.
\end{abstract}




\section{Keywords}

Racial discrimination, Rental housing, Field experiment

\section{Introduction}

The Department of Housing and Urban Development (HUD) annually receives between 700 and 1000 complaints alleging discrimination on the basis of race or national origin, ${ }^{2}$ and spends approximately $\$ 25$ million on enforcing Fair Housing Laws. About $2 \%$ of all complaints end with a charge of discrimination, and about $1 \%$ end in a referral to the Department of Justice (DOJ) for enforcement. In fiscal year 2010, DOJ actions resulted in over $\$ 1$ million in penalties for Fair Housing Law violators, not including out of court settlements. ${ }^{3}$ Despite the dollars spent on enforcement and penalties landlords, real estate agents, and mortgage brokers face for violating these laws, racial discrimination is still apparent in housing markets across the U.S. ${ }^{4}$ The dollars spent on enforcement of Fair Housing Laws and the fact that agents still violate them leads to at least two questions: What motivates agents to discriminate? And, are there ways to reduce the cost of identifying violators?

This paper examines how discrimination changes with neighborhood and housing unit characteristics, which offers insight into the causes of racial discrimination in housing markets and identifies areas where agents are most likely to violate Fair Housing Laws. We measure discrimination using data from a within-subjects field experiment, or matched-pair housing audit of landlords advertising rental housing on-line. The experiment communicates with landlords via e-mail, using names to signal race, and measures differential response rates between African Americans and whites. We match our measure of discrimination to data on housing unit and 2010 Census neighborhood characteristics.

We use a local polynomial smoothing estimation procedure to find where in the distribution of characteristics discrimination is more likely to occur. This estimation method provides a smooth prediction of discrimination outcomes across various characteristics of the neighborhood or housing unit. Local polynomial smoothing is advantageous in this setting as it does not assume a functional form for where discrimination may occur, it allows the data to determine the relationship. We examine several different dimensions of neighborhood and housing unit characteristics including, racial composition, distance to the city center, rental rates, and vacancy rates.

The results suggest that there are particular areas within cities that are more prone to higher rates of discrimination against African American home-seekers. African Americans face higher rates of discrimination than whites in a wide range of racially mixed neighborhoods, in higher rent areas, closer in to the center city, and in low vacancy areas. The different locations of increased discrimination provide evidence that supports several hypotheses on the cause of discrimination. Generally, the results suggest current/future customer prejudice or perceived preference as a cause of discrimination and do not support landlord taste as a cause. The results also suggest that targeting enforcement efforts to particular areas of cities may help to reduce costs.

The next section of the paper is a discussion of the previous research on housing market discrimination, and describes how examining where discrimination occurs can inform the causes of discrimination. Section 3 describes the experimental design and neighborhood data. Section 4 outlines the methodology for examining discrimination across neighborhood characteristics using non-parametric estimation. Section 5 presents the results, and the final section of the paper concludes.

\section{Background and causes of discrimination}

Discrimination against racial minorities in the housing market is well documented by experimental studies. ${ }^{5}$ These studies typically use data from pairs of actors that visit real estate agent offices on separate occasions and record treatment to researchers. Matched pair, or within-subjects experiments, often referred to 
as audits, began with Yinger (1986) and continue to be used in the literature to study discrimination today. Other studies that use data from in-person, matched pair experiments include Yinger (1991), Roychoudhury and Goodman (1992), Page (1995), Ondrich et al. (1998), Ondrich et al. (1999), Ondrich et al. (2000), and Ondrich et al. (2003), Choi et al. (2005), Zhao (2005), and Zhao et al. (2006). More recently, correspondence studies that use names to identify race, and e-mail communication, have appeared in the literature. These studies maintain the advantages of the experimental design, but avoid some of the problems associated with using in-person actors (see Heckman (1998) and Heckman and Siegelman (1993) for a detailed critique of in-person experiments). Studies that use e-mail based communication to study discrimination in the housing market include Carpusor and Loges (2006), Ahmed and Hammarstedt (2008), Ahmed et al. (2008), Ahmed and Hammarstedt (2009), Ewans et al. (forthcoming), Ahmed et al. (2010), Bosch et al. (2010), Hanson and Hawley (2011), and Hanson et al. (2011).

All of the literature that examines discrimination in the housing market finds that discrimination occurs against minority clients to some degree. The literature examines a variety of ways that housing agents may practice unequal treatment of minority clients, including steering, providing information on or showing additional units, or asking for future visit opportunities. The Hanson et al. (2011) study even examines the text of landlord replies to inquires about rental housing to show that landlords use more positive language and are more descriptive about units when replying to white customers.

We extend this literature along the lines of Yinger (1986) to examine the characteristics of neighborhoods where discrimination happens, and use this to inform the likely cause of discrimination. Yinger (1986) hypothesizes three causes of discrimination in housing markets, and how they relate to the racial composition of neighborhoods. ${ }^{6}$

The first hypothesis Yinger describes is that agents (landlords) discriminate because of their own tastes or prejudice in dealing with minority clients. Yinger points out that this cause of discrimination may vary with landlord characteristics. For our purposes, because we do not have data on landlord characteristics, this cause of discrimination should result in a constant relationship between neighborhood characteristics and discrimination.

The second hypothesis is that landlords discriminate because they act on behalf of prejudice customers (current or future tenants). This cause of discrimination is driven by statistical discrimination as described by Phelps (1972). Statistical discrimination implies an agent (landlord) uses past experiences to formulate the expected payoff for each potential home-seeker and selects a lessee by profit maximization. This type of discrimination may also be linked to landlords attempting to prevent the surrounding neighborhood from "tipping" beyond an acceptable minority share for white residents, as described in Card et al. (2008). Once a neighborhood reaches a tipping point share of minorities, it tends to become all minority residents, as whites find the neighborhood unacceptable. Another form of perceived prejudice that landlords may react to is from local public goods provision. Alesina et al. (1999) show that areas with more ethnic fragmentation spend less on 'productive' public goods, such as education, roads, sewers, and trash pickup. If landlords care about the level of local public goods provided in their area, they may intentionally try to keep minorities from locating in their communities in order to keep the level of local public goods high.

Lastly, the landlord may treat minority and white clients differently because of what they perceive to be different preferences for neighborhoods or housing units among these groups. This would again be considered statistical discrimination by the definition in Phelps (1972). Yinger points out, and the Card et al. (2008) study confirms, that whites have a preference for neighborhoods with a vast white majority of residents. African Americans, on the other hand, have preference for integrated neighborhoods. 


\section{Experimental design and data}

The key elements of studying where housing market discrimination occurs are an unbiased measure of discrimination, and data on local neighborhood characteristics. Our unbiased measure of discrimination comes from a field experiment conducted by Hanson and Hawley (2011). For data on neighborhood characteristics, we match the address of housing units in Hanson and Hawley (2011) to 2010 census tract level neighborhood characteristics using ArcGIS software.

The Hanson and Hawley (2011) field experiment is a within-subjects, or matched pair audit correspondence study, of landlords across the United States. ${ }^{7}$ The data come from landlords of rental properties advertised on Craigslist.org. Craigslist allows participants to place and reply to on-line advertisements specific to local markets for jobs, housing, companionship, and other goods and services, although the experiment uses only listings pertaining to the rental housing market. Each landlord is sent two emails, one from an email address associated with a white name and one email from an address with an African American name. The experiment design relies on the names of the potential renters to signal race to the landlord.

The fictitious renters' names come from Bertrand and Mullainathan (2004), who use Massachusetts birth certificate data from 1974 to 1979 to identify names highly associated with each race. The first names used to designate a white renter are Brad, Brendan, Brett, Matthew, Neil, Geoffrey, Todd, Greg, and Jay. The first names used to identify an African American renter are Darnell, Hakim, Jamal, Jermaine, Kareem, Leroy, Rasheed, Tremayne, and Tyrone. The last names for white renters are Davis, Ryan, Murphy, O'Brien, Baker, McCarthy, Young, Jones, and Wright. The last names used to represent African American renters are Johnson, Washington, Robinson, Jackson, Hall, Parker, Williams, Jones, and Cooper.

The experiment consists of 4728 audits, or 9456 e-mail inquiries to advertisements for rental housing from Atlanta, Boston, Chicago, Dallas, Washington, D.C., Houston, Los Angeles, New York, Seattle, and San Francisco. All e-mail inquiries are sent between 9 am and 12 pm on the day after a landlord posts an advertisement (always a Wednesday). Inquiries are sent from g-mail account addresses in the following format: firstname.lastname.\#\#\#@gmail.com, where \#\#\# is a three-digit number unique to each name. The overall response rate to e-mail inquiries is $53.9 \%$, with $63.6 \%$ of landlords responding to at least one e-mail inquiry from a pair of e-mails.

We use approximately 2000 audits from the original experiment that include one African American and one white name, the exact number depends on the neighborhood characteristic we examine. ${ }^{8}$ We examine discrimination across neighborhood demographics by identifying the addresses of the advertised housing units, and matching them to census information. The neighborhood information is determined at the census tract level. The address for each of the rental properties is geo-coded and identified with a unique census tract. With the census tract id information, we match the 2010 census data for each location and corresponding audit.

\section{Estimating discrimination rates across neighborhood characteristics}

We use the within-subjects experimental design to determine if a given landlord treats email inquiries equally or discriminates by only replying to one e-mail. To measure discrimination across characteristics, we calculate the discrimination rate against African Americans and whites. The discrimination rate against African Americans (whites) is the ratio of landlords that responded to the white (African American) home-seeker but not to the African American (white) home-seeker divided by the number of audits.

$$
D_{\text {Rate }}^{A A}=\frac{\# \text { ofrepliestoonlywhiteauditor }}{\text { \#ofaudits }}
$$


We calculate a discrimination rate for each "bin" in our non-parametric specification, where the size of the bin depends on the characteristic in question and the distribution of each variable. This means that we are aggregating landlords that rent units in census tracts with similar characteristics to create a discrimination rate. The original experiment measures discrimination at the landlord level, using one unit per landlord so that we are not counting discriminating (or non-discriminating) landlords more than once.

There are four different characteristics for which we evaluate the changes in the discrimination rates. Table 1 provides a description and summary statistics for each of the neighborhood characteristics. The most influential neighborhood characteristic for discrimination studies is the population racial composition. We use the percentage of white residents within the neighborhood as the characteristic of interest. The average percentage of white residents in the sample is $61.8 \%$. The second characteristic is how far the neighborhood is from the city center. We calculate the distance measure as straight-line distance from the centroid of the neighborhood, or census tract, to the tallest building for each respective city. The average distance to the city center for units in our sample is 10.6 miles.

Table 1. Summary statistics.

\begin{tabular}{|l|l|l|l|l|l|l|}
\hline Variable & Description & Obs. & Mean & $\begin{array}{l}\text { St. } \\
\text { dev. }\end{array}$ & Min & Max \\
\hline $\begin{array}{l}\text { Percentage of white } \\
\text { residents }\end{array}$ & The percentage of white residents. & 2029 & 0.618 & 0.236 & 0.005 & 1 \\
\hline Distance to city center & $\begin{array}{l}\text { The straight line distance to the city } \\
\text { center (proxied by tallest building) } \\
\text { in miles. }\end{array}$ & 2207 & 10.605 & 10.881 & 0.136 & 113.495 \\
\hline Rental rate & $\begin{array}{l}\text { The advertised rental rate set by the } \\
\text { landlord. }\end{array}$ & 2009 & 1488.04 & 769.37 & 250 & 8750 \\
\hline Rental rate ratio & $\begin{array}{l}\text { The ratio of the advertised rental } \\
\text { rate divided by the median rent for } \\
\text { the city. }\end{array}$ & 2009 & 1.080 & 0.437 & 0.169 & 4.714 \\
\hline Vacancy rate & $\begin{array}{l}\text { The percentage of rental properties } \\
\text { that are for rent and vacant. }\end{array}$ & 2026 & 0.042 & 0.037 & 0 & 0.591 \\
\hline $\begin{array}{l}\text { Gross discrimination rate } \\
\text { against whites }\end{array}$ & $\begin{array}{l}\text { The percentage of landlords who } \\
\text { only responded to the African } \\
\text { American client in the audit pair. }\end{array}$ & 2207 & 7.612 & 26.525 & 0 & 100 \\
\hline $\begin{array}{l}\text { Gross discrimination rate } \\
\text { against African } \\
\text { Americans }\end{array}$ & $\begin{array}{l}\text { The percentage of landlords who } \\
\text { only responded to the White client } \\
\text { in the audit pair. }\end{array}$ & 2207 & 13.14 & 33.791 & 0 & 100 \\
\hline Central city & $\begin{array}{l}\text { = } 1 \text { if rental location is within the } \\
\text { urbanized area }\end{array}$ & 2207 & 0.977 & 0.147 & 0 & 1 \\
\hline
\end{tabular}

Most units advertised on craigslist include an advertised rent, and we use this information, combined with data on city median rents to create a ratio of median rent for each unit in our sample. ${ }^{9}$ We use a ratio, rather than the nominal value of rent for each unit, to control for the vast differences in nominal rent values across the areas studied. The rent ratio provides insight to the level of discrimination in higher public good areas, as these qualities of the neighborhood are usually reflected in higher rents. The average landlord advertised rental rate is $\$ 1488.04$, and the average rental ratio is 1.08 , close to the median rent for the city. 
To understand how the supply of rental units in the neighborhood may affect discrimination, we calculate the vacancy rate as the number of for rent vacant rental units divided by the number of rental households. ${ }^{10}$ The average vacancy rate for neighborhoods in our sample is $4.2 \%$.

Table 1 also shows the gross discrimination rate against African Americans as $13.1 \%$ which is the percentage of audits where the landlord only responded to the white potential client. The gross discrimination rate against whites, or the percentage of audits where the landlord only responded to the African American potential client, is $7.6 \%$. The indicator variable for central city is unity for housing units lying inside an urbanized area. ${ }^{11}$

Table 2 summarizes how each of the neighborhood characteristics we examine relates to the Yinger hypotheses on the causes of discrimination. The simplest hypothesis is the landlord taste-based discrimination. The taste hypothesis states that the level of discrimination should not vary with the characteristics of the neighborhood but only due to the characteristic of the home-seeker. The resulting expectation is constant discrimination against African American home-seekers and no discrimination against white home-seekers.

Table 2. Cause of discrimination hypotheses by neighborhood characteristic.

\begin{tabular}{|c|c|c|c|c|}
\hline & Landlord taste & $\begin{array}{l}\text { Current or future } \\
\text { customer }\end{array}$ & Prevent tipping & $\begin{array}{l}\text { Perceived } \\
\text { preference/budget }\end{array}$ \\
\hline \multirow[t]{3}{*}{$\begin{array}{l}\text { Racial } \\
\text { composition }\end{array}$} & $\begin{array}{l}\text { Discrimination } \\
\text { against African }\end{array}$ & $\begin{array}{l}\text { Decreasing } \\
\text { discrimination } \\
\text { against African }\end{array}$ & $\begin{array}{l}\text { Discriminate against } \\
\text { African }\end{array}$ & $\begin{array}{l}\text { Discriminate against } \\
\text { African }\end{array}$ \\
\hline & $\begin{array}{l}\text { Americans } \\
\text { everywhere }\end{array}$ & $\begin{array}{l}\text { Americans as white } \\
\text { population declines }\end{array}$ & $\begin{array}{l}\text { Americans in } \\
\text { neighborhoods rises } \\
\text { sharply in tipping } \\
\text { range, falls on either } \\
\text { side of this range }\end{array}$ & $\begin{array}{l}\text { Americans in } \\
\text { neighborhoods that are } \\
\text { vast majority white }\end{array}$ \\
\hline & $\begin{array}{l}\text { No discrimination } \\
\text { against whites }\end{array}$ & $\begin{array}{l}\text { Increasing } \\
\text { discrimination } \\
\text { against whites, as } \\
\text { white population } \\
\text { declines }\end{array}$ & $\begin{array}{l}\text { Discriminate against } \\
\text { whites in } \\
\text { neighborhoods rises } \\
\text { sharply in tipping } \\
\text { range, falls on either } \\
\text { side of this range }\end{array}$ & $\begin{array}{l}\text { Increasing discrimination } \\
\text { against whites, as white } \\
\text { population declines }\end{array}$ \\
\hline \multirow[t]{2}{*}{$\begin{array}{l}\text { Distance to } \\
\text { city center }\end{array}$} & $\begin{array}{l}\text { Discrimination } \\
\text { against African } \\
\text { Americans } \\
\text { everywhere }\end{array}$ & $\begin{array}{l}\text { Discriminate against } \\
\text { African Americans in } \\
\text { neighborhoods } \\
\text { further from the city } \\
\text { center }\end{array}$ & Not relevant & $\begin{array}{l}\text { Discriminate against } \\
\text { African Americans in } \\
\text { neighborhoods further } \\
\text { from the city center }\end{array}$ \\
\hline & $\begin{array}{l}\text { No discrimination } \\
\text { against whites }\end{array}$ & $\begin{array}{l}\text { Discriminate against } \\
\text { whites in } \\
\text { neighborhoods } \\
\text { closer to city center }\end{array}$ & Not relevant & $\begin{array}{l}\text { Discriminate against } \\
\text { whites in neighborhoods } \\
\text { closer to city center }\end{array}$ \\
\hline \multirow[t]{2}{*}{ Rental rate } & $\begin{array}{l}\text { Discrimination } \\
\text { against African } \\
\text { Americans } \\
\text { everywhere } \\
\end{array}$ & $\begin{array}{l}\text { Discriminate against } \\
\text { African Americans } \\
\text { more as rental rate } \\
\text { increases }\end{array}$ & Not relevant & $\begin{array}{l}\text { Discriminate against } \\
\text { African Americans more } \\
\text { as rental rate }\end{array}$ \\
\hline & $\begin{array}{l}\text { No discrimination } \\
\text { against whites }\end{array}$ & $\begin{array}{l}\text { No discrimination } \\
\text { against whites }\end{array}$ & Not Relevant & $\begin{array}{l}\text { No discrimination } \\
\text { against whites, or } \\
\text { discrimination at lowest } \\
\text { rents }\end{array}$ \\
\hline
\end{tabular}




\begin{tabular}{|l|l|l|l|l|}
\hline Vacancy rate & $\begin{array}{l}\text { Discrimination } \\
\text { against African } \\
\text { Americans } \\
\text { everywhere }\end{array}$ & $\begin{array}{l}\text { Reduced } \\
\text { discrimination } \\
\text { against African } \\
\text { Americans as } \\
\text { vacancy rate rises }\end{array}$ & Not relevant & $\begin{array}{l}\text { Discrimination against } \\
\text { African Americans as } \\
\text { vacancy rate falls }\end{array}$ \\
\hline $\begin{array}{l}\text { No discrimination } \\
\text { against whites }\end{array}$ & $\begin{array}{l}\text { Less discrimination } \\
\text { against whites as } \\
\text { vacancy rates rise }\end{array}$ & Not relevant & $\begin{array}{l}\text { More discrimination } \\
\text { against whites as } \\
\text { vacancy rates rise }\end{array}$ \\
\hline
\end{tabular}

The second hypothesis tested is the current or future customer's prejudice. Under this hypothesis, landlords should discriminate more against one race when the surrounding population is of a different race. If the belief of the landlord is that current or future tenants who live in more homogenous neighborhoods want to continue to live in such neighborhoods, then landlords may discriminate more when the race of the home-seeker does not match the current demographic. An additional hypothesis that provides a very similar story is the tipping phenomenon. Tipping may appear as a desire for integration at very high percentage majority population followed by a rapid increase in discrimination against minority home-seekers as the neighborhood approaches the tipping point. This behavior is consistent with the current population trying to 'save' the neighborhood. After the tipping point is achieved, the hypothesis predicts a decline in discrimination rates against minority clients as the majority leaves and the neighborhood becomes fully integrated.

The final hypothesis is the perceived preference or budget of a perspective client. If perceived customer preferences are driving landlord discrimination, we should find discrimination against whites in majorityminority neighborhoods, and discrimination against African Americans only in vast majority white neighborhoods. Landlords in neighborhoods with very high percentages of white residents may not believe that an African American would truly want to live in their unit. The email inquiry may not be seen as genuine interest and thus the landlord does not respond. The perception is that each race may prefer a small amount of integration, but in neighborhoods with virtually no integration landlords may not see an inquiry as genuine interest.

The primary method for analyzing the audit data is a local polynomial smoothing technique. This estimation strategy combines the simplicity of a parametric method, Weighted Least Squares (WLS), with the flexibility of a non-linear regression technique. The estimation fits multiple WLS regressions to 'localized' bins of the data building a more flexible result that is determined by the variation within the data, point-by-point.

$$
\min \sum_{i=1}^{n} w_{i}\left(y_{i}-x_{i} \beta\right)^{2}
$$

The data within the bin that surrounds the point of interest are weighted with increased importance given the 'closer' data. The same estimation is applied for all data points in the distribution, shifting 'localized' bins accordingly. The resulting smooth function, $f$, is a compilation of each point's WLS predicted value.

$$
y_{i}=f\left(x_{i}\right)+\varepsilon_{i}
$$

The local polynomial smoothing method, introduced by Cleveland (1979) and refined by Cleveland and Devlin (1988), places the resulting fitted values into a plot or functional form that is not possible to estimate with parametric techniques. The biggest benefit to using smoothing as opposed to standard linear regression is that it does not require a global functional form assumption of the underlying distribution of the data, only for each bin of the data. An additional benefit of the smoothing is that many of the parameters such as the degree of 
polynomial, bandwidth (size of the 'localized' bin), or weights, are flexible in the estimation. We choose local polynomial over other techniques, such as spline estimation, because it allows the data to determine where (or if any) structural breaks occur.

The local polynomial smoothing technique also allows for confidence interval calculation. We use the confidence intervals to determine significant differences in the discrimination rates against either race along the distribution of the characteristic. These differences inform the plausibility of the underlying causes.

Using local polynomial smoothing requires us to make three choices - the degree of polynomial estimate within bins, the bandwidth around each point, and the weights assigned to other points around each data point. Cleveland (1979) discusses choosing the degree of polynomial and finds that linear smoothing is almost always an adequate balance between flexibility and computational ease. The choice of higher degree polynomials does not change the results and only makes the intuition of the method more cumbersome. We must also choose a bandwidth around each observation to define how much of the data to use in each regression, we use the "rule of thumb" bandwidth. ${ }^{12}$ The Appendix A examines sensitivity of our results to this choice. The weights are kernel distributed. ${ }^{13}$ DiNardo and Tobias (2001) point out that, in general, nonparametric estimates are not sensitive to the choice of how nearby observations are weighted.

The local polynomial smoothing method is not a new empirical method in urban economics. Meese and Wallace (1991) use the nonparametric technique to evaluate hedonic price models and residential housing price indices. McMillen (1996) applies the locally weighted estimates to land value data from Chicago over the past 150 years. The flexibility of the model helps provide insights on the polycentric nature of Chicago. More recently, McMillen and Redfearn (2010) show how hypothesis testing can be done with the local polynomial smoothing method. We are advancing this line of literature by using this flexible empirical method to analyze the location of discrimination across urban areas.

\section{Results}

\subsection{Percent of white residents}

Fig. 1 shows the discrimination rates across the racial composition of the neighborhood surrounding rental properties in our data. The discrimination rate against African American home-seekers is significantly higher than against white home-seekers across the full range of neighborhoods. Discrimination against white homeseekers does not fluctuate across neighborhood composition, which suggests racial composition is not important in determining the level of discrimination against whites.

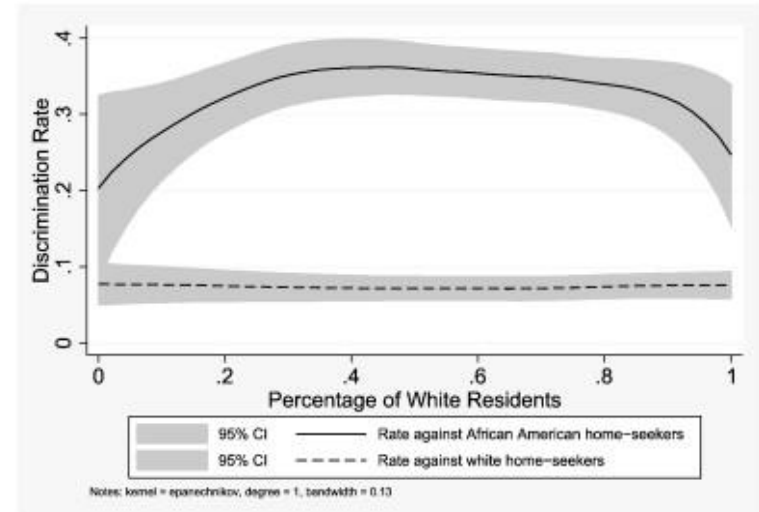

Fig. 1. Local linear smoothing by percentage of white residents. 
If we start at a location where the neighborhood comprises $100 \%$ white residents and slowly add minority households, we see the discrimination rate against African American home-seekers rises steadily. The current residents may be fearful of their neighborhood tipping, as the discrimination rate reaches a plateau at around $80 \%$ white residents. This result is consistent with Card et al. (2008) as most of the neighborhoods showed tipping between 10 and $20 \%$ minority. There is no drop off in discrimination rates between $80 \%$ and $30 \%$ white residents which is not consistent with the expectation of tipping concerns. African American home-seekers face similar discrimination rates for a large range of mixed neighborhoods. Below $30 \%$ white residents, the discrimination rate falls, implying residents in neighborhoods with a large percentage of minority residents do not discriminate against African Americans as much as the landlords in mixed neighborhoods. This figure is not consistent with current or future customer prejudice, since the expectation under this hypothesis is higher levels of discrimination in largely white or African American neighborhoods. It is also not consistent with landlord taste-based discrimination as the rate of discrimination does significantly change with the racial composition.

Fig. 2, Fig. 3, Fig. 4, Fig. 5 show examples of different city specific cases for discrimination by the percent of white residents in the surrounding neighborhood, as discrimination may differ across the distribution in each city. ${ }^{14}$ In Atlanta, the discrimination rate against white home-seekers falls as the percentage of white residents becomes larger. This is consistent with customer prejudice against living with white residents. Additionally, there is only a small significant difference in discrimination rates between African Americans and whites for Atlanta, and the location of this difference is consistent with a tipping concern story. As the minority population grows, so does the discrimination rate, but the rate begins to decline at around $75 \%$ white residents.

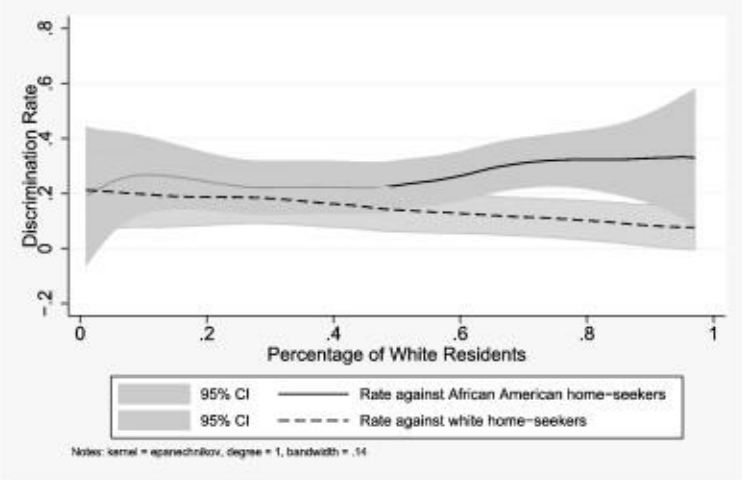

Fig. 2. Local linear smoothing by percentage of white residents Atlanta sub-case.

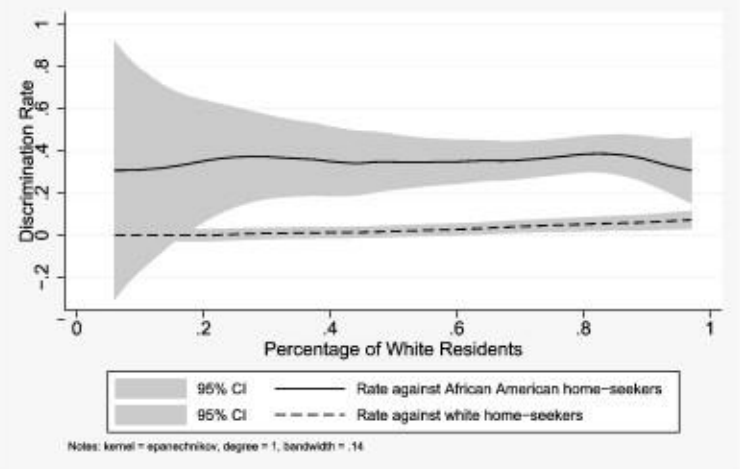

Fig. 3. Local linear smoothing by percentage of white residents Boston sub-case. 


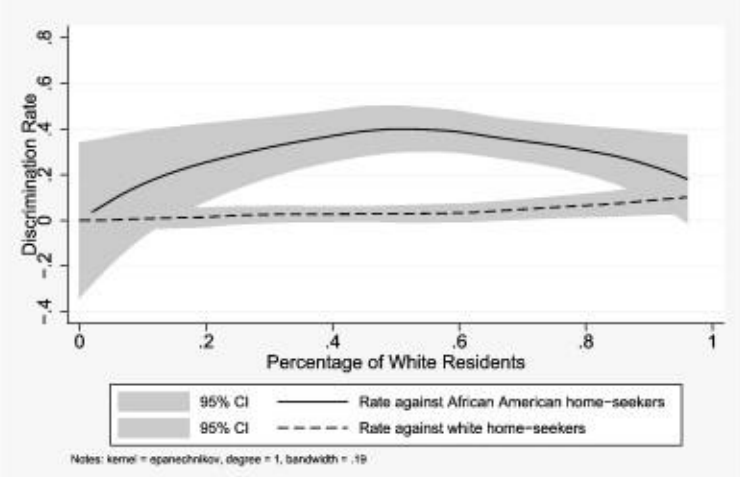

Fig. 4. Local linear smoothing by percentage of white residents Chicago sub-case.

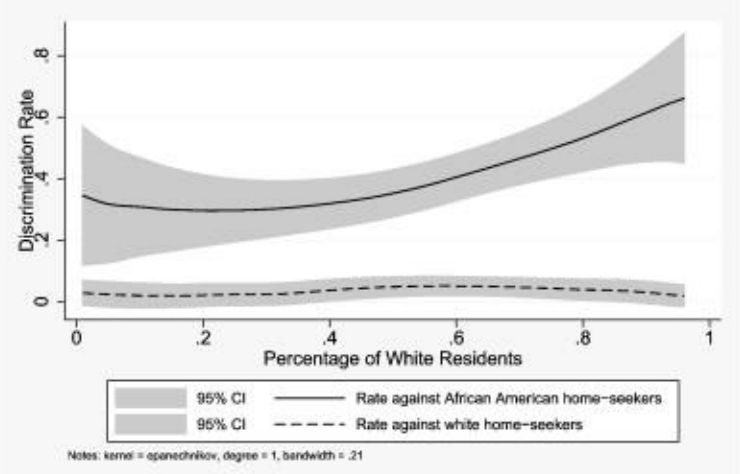

Fig. 5. Local linear smoothing by percentage of white residents District of Colombia sub-case.

Fig. 3 describes the Boston sub-case. There seems to be a constant discrimination rate difference against African Americans in Boston. Over a wide range of neighborhood compositions, below $85 \%$ white, the predicted difference is stable. ${ }^{15}$ Above 85 or $90 \%$, the discrimination rate against African Americans does fall slightly this is again suggestive of a neighborhood tipping concern story. The Chicago sub-case tells a different

story. Fig. 4 shows a desire for integration in neighborhoods that are highly white concentrated, as the rate of discrimination is not statistically different between white or African American home-seekers. However, as the minority share continues to climb, the difference becomes significant and peaks around $50 \%$. This pattern may be consistent with perceived preference discrimination. Landlords may believe African Americans want to live in either mainly white neighborhoods or largely minority neighborhoods with less desire to be in the middle.

Fig. 5 presents the District of Columbia sub-case. The highest rates of discrimination appear in the white concentrated neighborhoods and falls off steadily with the percentage of white residents. This city's sub-case is most consistent with the customer prejudice hypothesis. Landlords may believe that current neighbors or future clients will not appreciate integration in their neighborhoods and these preferences can produce a picture like the D.C. sub-case.

\subsection{Distance to city center}

With the stark difference in housing structures and social interaction within urban and suburban neighborhoods, examining discrimination rates by distance from center of the city may provide insight into how these factors influence discrimination. Fig. 6 shows the discrimination rate against African American home-seekers is always higher than whites across the entire distance distribution, although the rates do pinch together slightly at around 20 to 30 miles from the city center. Again, since the individual cities vary greatly on the types of neighborhoods at various distances, we look at the individual sub-cases to reveal more about potential causes. ${ }^{16}$ 


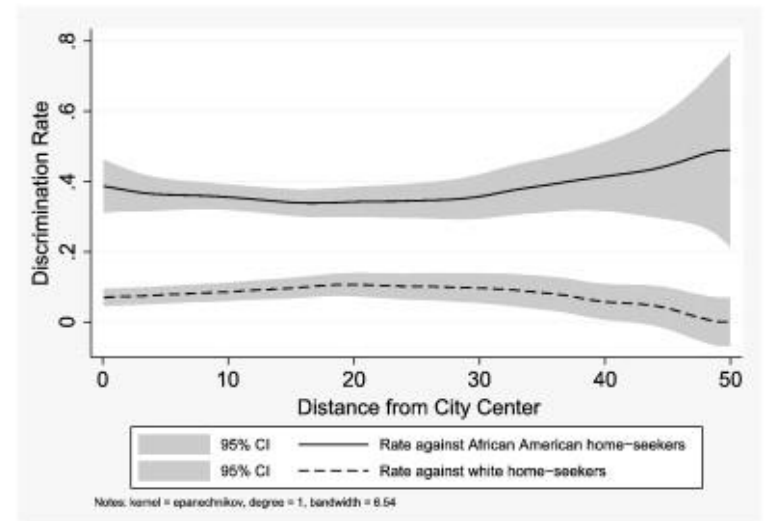

Fig. 6. Local linear smoothing by distance from city center.

Fig. 7 shows the Atlanta sub-case. This figure shows a preference for integration very close to the city center as well as in the suburbs between 15 and 30 miles away. Interestingly, there are two ranges of distances for which the discrimination rates are significantly different. In the urban setting from about 2 miles to 15 miles out and in the outer suburb ring (between 30 and 40 miles), where the discrimination rate against African American homeseekers is statistically larger than against white home-seekers. This type of pattern may suggest customer prejudice as the landlords are likely aware of the clientele of those neighborhoods. ${ }^{17}$ The Chicago sub-case is similar as shown in Fig. 9.

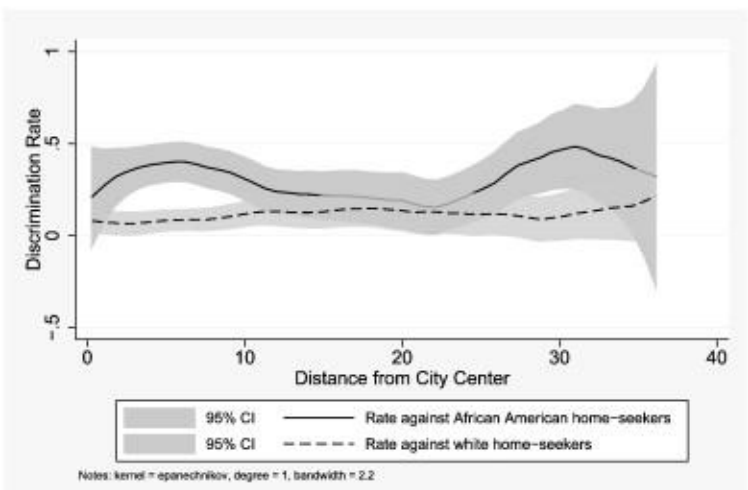

Fig. 7. Local linear smoothing by distance from city center Atlanta sub-case.

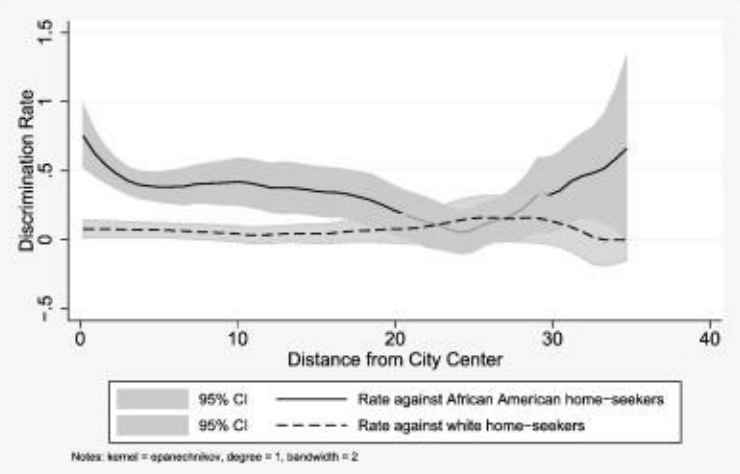

Fig. 8. Local linear smoothing by distance from city center Boston sub-case. 


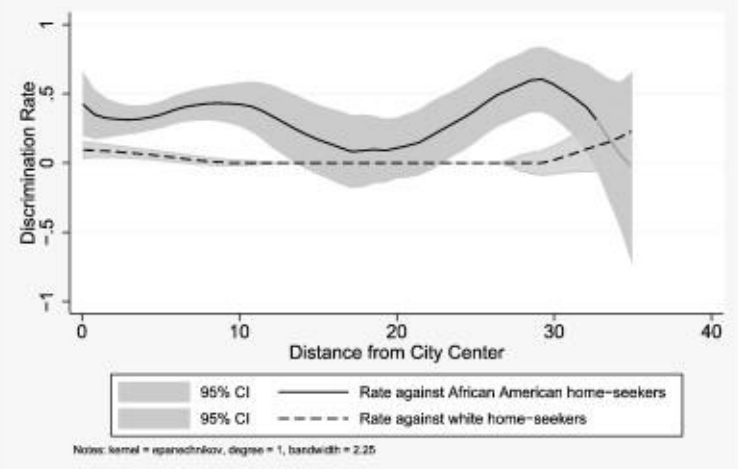

Fig. 9. Local linear smoothing by distance from city center Chicago sub-case.

Fig. 8 describes the discrimination rate difference across distance for the Boston sub-case. In this case there does not seem to be a preference for integration near the city center but as the distance is increased the difference in discrimination rate goes away. Fig. 10 shows the District of Columbia sub-case which is similar to Boston in that there is a statistically significant difference very close to the city center. This difference disappears as the distance increases, but unlike Boston, in the further suburbs the difference reemerges.

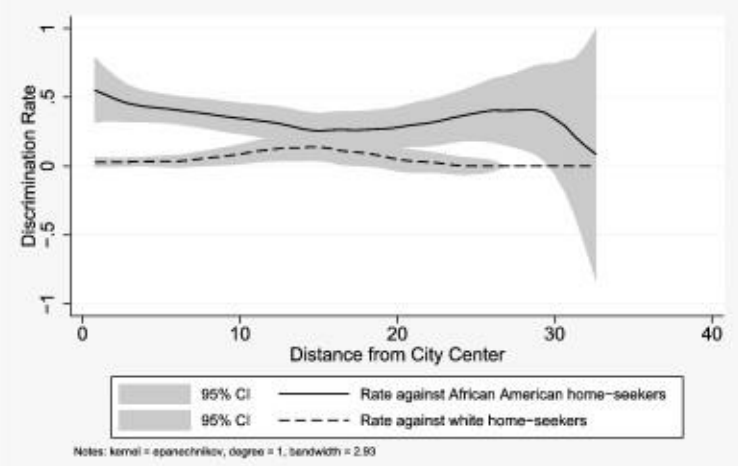

Fig. 10. Local linear smoothing by distance from city center District of Colombia sub-case.

\subsection{Advertised rental rate}

Fig. 11 presents the discrimination rates over the advertised rent relative to the median rent. At low rents relative to the median, there is no statistical difference in differential treatment against white or African American home-seekers. There is a large increase in discrimination against white home-seekers in the lower range. It may be that landlords do not believe the typical white customer will want to live in a low-rent area, and discriminates against them due to perceived preference. 


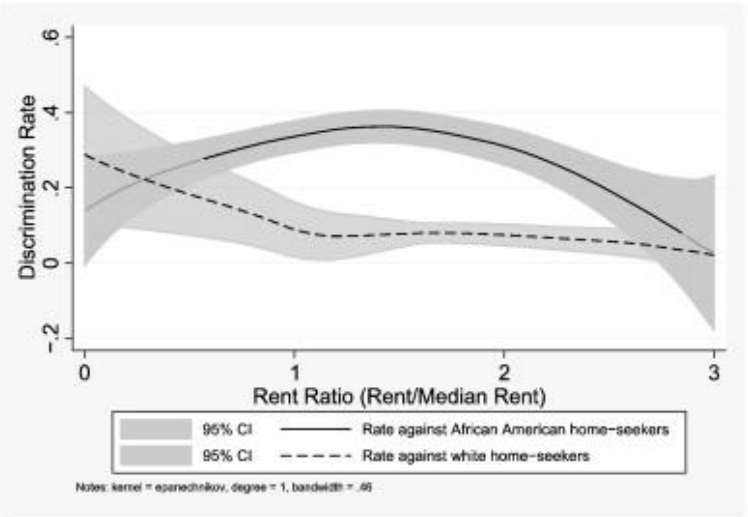

Fig. 11. Local linear smoothing by rent ratio.

When the rent ratio reaches around 0.75 , or at rents above $75 \%$ of the median, landlords start to discriminate more against African Americans than their white counterparts. This difference in discrimination rates continues to rise and peaks at around 1.5, or at rents that are $150 \%$ of the median. This type of result is suggestive of statistical discrimination, if the landlord has a perception of ability to pay from the racial group. Interestingly, as the rent ratio continues to increase the discrimination rates become closer and eventually not statistically different from each other. This suggests in very expensive areas landlords are not favoring African Americans or whites disproportionately, at least through initial email contact. This does not occur until very high levels of rent, where even inquiring about a rental unit may send a strong signal about ability to pay.

In the city-specific cases, Atlanta (Fig. 12) and Boston (Fig. 13) are similar to the national average. The Chicago (Fig. 14) and D.C. (Fig. 15) sub-cases, there is statistically significant discrimination at the lower part of the rent ratio distribution that does not exist in the national sample. Although it is not entirely clear what is driving these differences, part of the reason may be the presence of other minority populations in Chicago and D.C. in low rent areas.

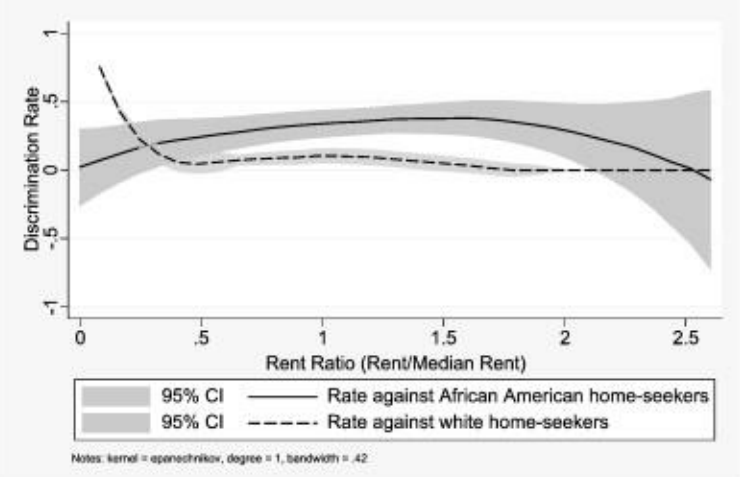

Fig. 12. Local Linear smoothing by rent ratio Atlanta sub-case. 


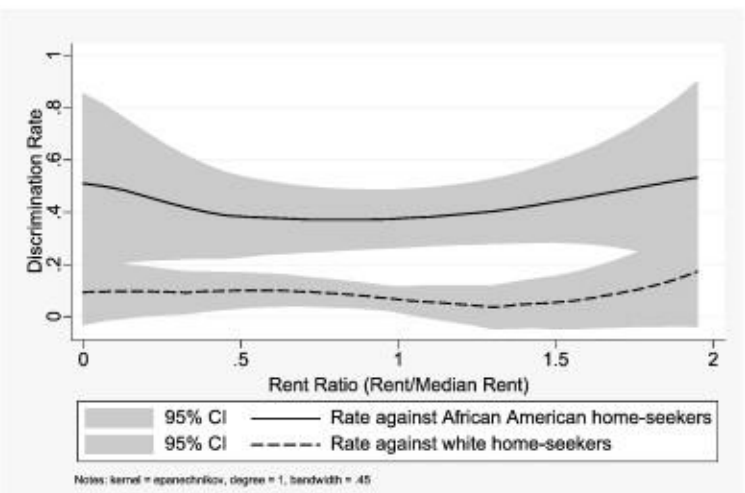

Fig. 13. Local linear smoothing by rent ratio Boston sub-case.

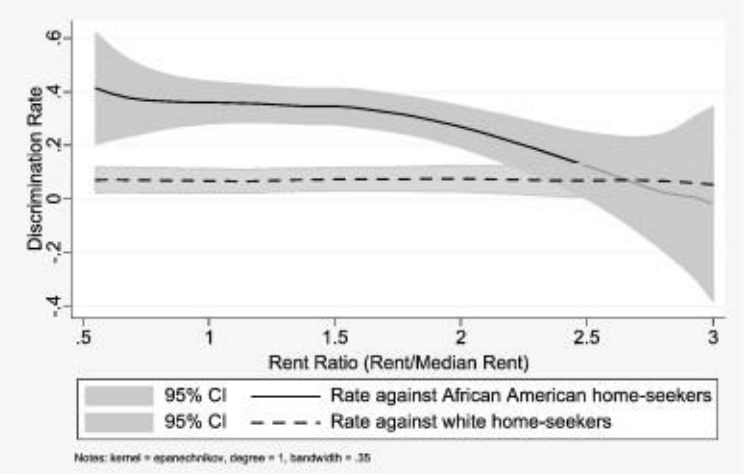

Fig. 14. Local linear smoothing by rent ratio Chicago sub-case.

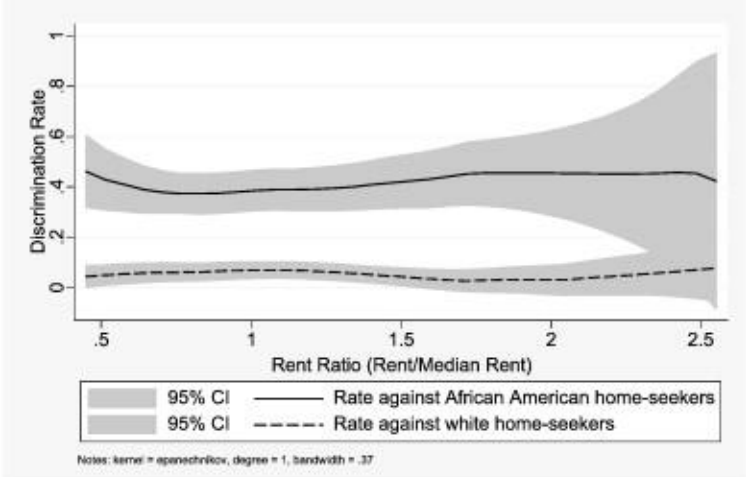

Fig. 15. Local linear smoothing by rent ratio District of Colombia sub-case.

\subsection{Neighborhood vacancy rate}

Fig. 16 examines discrimination across neighborhood vacancy rates. After a slow initial decline, the discrimination rate against African Americans rises sharply in neighborhoods starting with about $12 \%$ vacant units. This type of result is consistent with personal prejudice rather than other statistical discrimination hypotheses, as a profit maximizing landlord should rent to any client where marginal benefit exceeds marginal cost, and a client paying rent should be superior to leaving a unit empty in nearly all cases. 


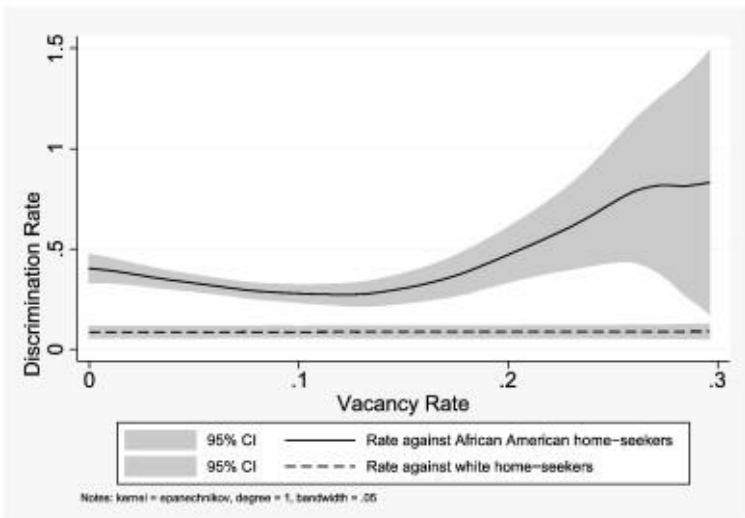

Fig. 16. Local linear smoothing by vacancy rate.

The Chicago sub-case (Fig. 19) shows a similar pattern to the national average, but all of the other city specific figures are substantially different. In Atlanta (Fig. 17) and the District of Columbia (Fig. 20), we find statistically meaningful discrimination against African Americans at low vacancy levels, and no discrimination at higher levels of vacancy-consistent with a statistical explanation, and not with landlord tastes, contrary to the national sample. Boston (Fig. 18) has the odd pattern of no discrimination at either high or low vacancy rates, but fairly constant discrimination in mid-level vacancy areas, although the vacancy distribution as a whole is shifted to the left.

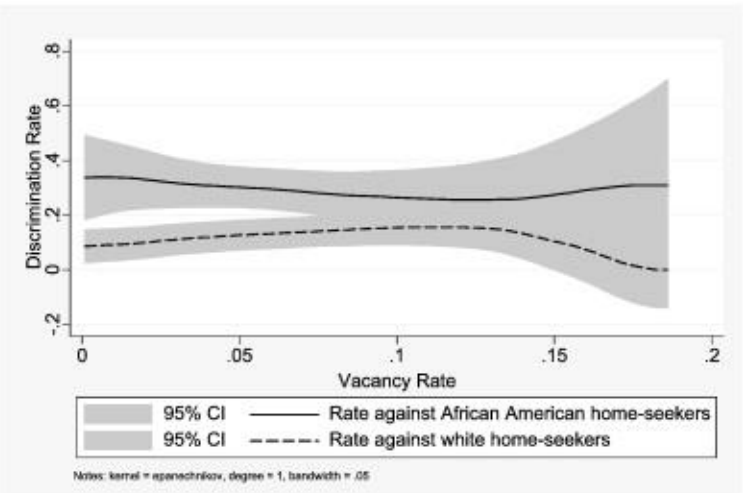

Fig. 17. Local linear smoothing by vacancy rate Atlanta sub-case.

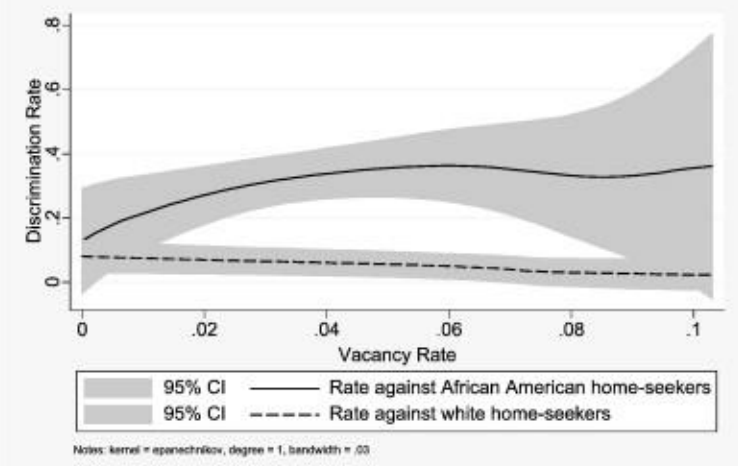

Fig. 18. Local linear smoothing by vacancy rate Boston sub-case. 


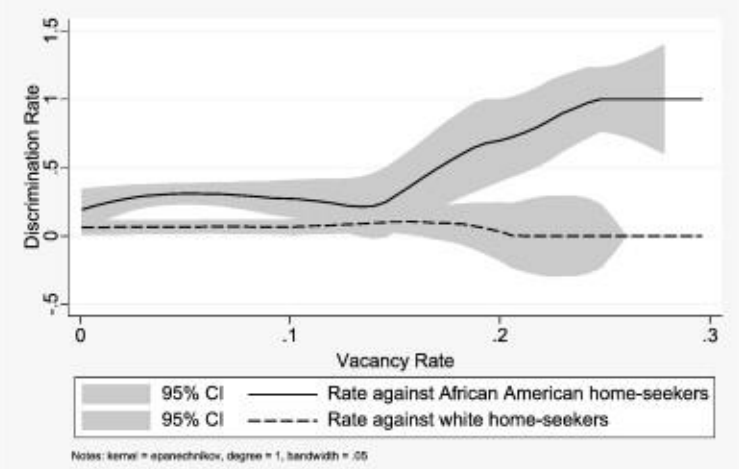

Fig. 19. Local linear smoothing by vacancy rate Chicago sub-case.

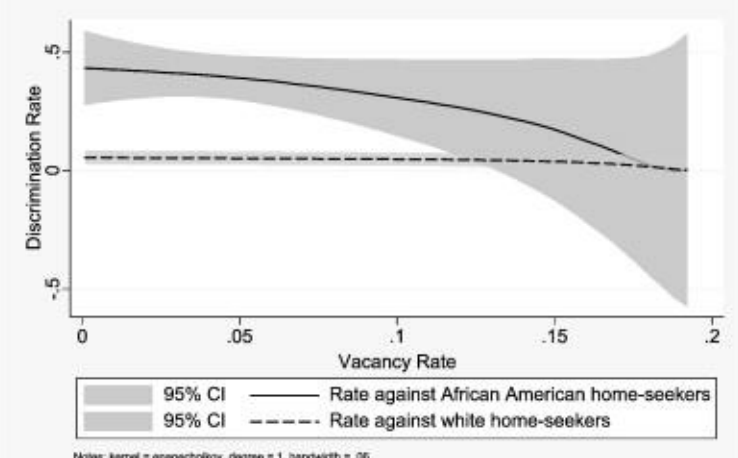

Fig. 20. Local linear smoothing by vacancy rate District of Colombia sub-case.

\subsection{Multivariate parametric results}

We use a multivariate nonlinear parametric model using simple polynomial to check that the nonlinear relationships shown in the bivariate nonparametric estimation stay consistent. This robustness check increases the confidence of our estimation strategy and results. Table 3 shows the nonlinear parametric results. We estimate a linear probability model with additional neighborhood and unit characteristic control variables such as number of bedrooms, number of bathrooms, and the percentage of college graduates in the census tract. The dependent variable is a binary response variable with unity implying a response was received. All of the previous unit and neighborhood characteristics are used as independent variables both together (column 1) and separately (columns 3-6). 
Table 3. Response rate by unit and neighborhood characteristics.

\begin{tabular}{|c|c|c|c|c|c|c|}
\hline & (1) & (2) & (3) & $(4)$ & (5) & (6) \\
\hline & $\begin{array}{l}\text { Combined } \\
\text { effect }\end{array}$ & $\begin{array}{l}\text { African } \\
\text { American } \\
\text { only effect }\end{array}$ & $\begin{array}{l}\text { Percentage of } \\
\text { white } \\
\text { residents } \\
\text { effect }\end{array}$ & $\begin{array}{l}\text { Distance } \\
\text { effect }\end{array}$ & $\begin{array}{l}\text { Median rent } \\
\text { ratio effect }\end{array}$ & $\begin{array}{l}\text { Vacancy } \\
\text { rate effect }\end{array}$ \\
\hline \multirow[t]{2}{*}{ African American (AA) } & 0.0106 & $-0.0542^{* * *}$ & 0.0131 & $-0.0530 * *$ & -0.0126 & $-0.0838 * * *$ \\
\hline & {$[0.10]$} & {$[-3.49]$} & {$[0.18]$} & {$[-2.03]$} & {$[-0.19]$} & {$[-2.92]$} \\
\hline \multirow[t]{2}{*}{ Percentage of white residents in the neighborhood } & $0.7137 * * *$ & & $0.7517 * * *$ & & & \\
\hline & [3.52] & & [3.71] & & & \\
\hline \multirow[t]{2}{*}{ Square of percentage of white residents } & $-0.5993 * * *$ & & $-0.5783 * * *$ & & & \\
\hline & {$[-3.23]$} & & {$[-3.12]$} & & & \\
\hline \multirow[t]{2}{*}{ AA $*$ Percentage of white residents } & -0.2842 & & -0.2866 & & & \\
\hline & {$[-0.99]$} & & {$[-1.01]$} & & & \\
\hline \multirow[t]{2}{*}{$A A *$ Square of percentage of white residents } & 0.2742 & & 0.2511 & & & \\
\hline & [1.05] & & {$[0.96]$} & & & \\
\hline \multirow[t]{2}{*}{ Distance to city center } & 0.0008 & & & 0.0017 & & \\
\hline & {$[0.36]$} & & & {$[0.82]$} & & \\
\hline \multirow[t]{2}{*}{ Square of distance to city center } & 0.0000 & & & 0.0000 & & \\
\hline & {$[0.68]$} & & & {$[0.46]$} & & \\
\hline \multirow[t]{2}{*}{ AA $*$ Distance to city center } & 0.0000 & & & -0.0001 & & \\
\hline & {$[0.02]$} & & & {$[-0.02]$} & & \\
\hline \multirow[t]{2}{*}{ AA $*$ Square of distance to city center } & -0.0000 & & & -0.0000 & & \\
\hline & {$[-0.11]$} & & & {$[-0.05]$} & & \\
\hline \multirow[t]{2}{*}{ Percentage of median rent in the city } & $0.1518^{* *}$ & & & & $0.1240 *$ & \\
\hline & {$[2.08]$} & & & & [1.80] & \\
\hline \multirow[t]{2}{*}{ Square of percentage of median rent in the city } & $-0.0523 * *$ & & & & $-0.0475 * *$ & \\
\hline & {$[-2.43]$} & & & & {$[-2.25]$} & \\
\hline \multirow[t]{2}{*}{$\mathrm{AA} *$ Percentage of median rent in the city } & -0.0525 & & & & -0.0558 & \\
\hline & {$[-0.52]$} & & & & {$[-0.58]$} & \\
\hline \multirow[t]{2}{*}{ AA $*$ Square of percentage of median rent in the city } & 0.0122 & & & & 0.0135 & \\
\hline & {$[0.40]$} & & & & {$[0.45]$} & \\
\hline \multirow[t]{2}{*}{ Vacancy rate in the neighborhood } & $-1.1315^{* *}$ & & & & & $-1.3643^{* * *}$ \\
\hline & {$[-2.16]$} & & & & & {$[-2.73]$} \\
\hline Square of vacancy rate in the neighborhood & $3.6450 * *$ & & & & & $4.0341 * * *$ \\
\hline
\end{tabular}




\begin{tabular}{|c|c|c|c|c|c|c|}
\hline & {$[2.35]$} & & & & & {$[2.65]$} \\
\hline \multirow[t]{2}{*}{ AA $*$ Vacancy rate in the neighborhood } & 0.8717 & & & & & 0.8206 \\
\hline & [1.18] & & & & & {$[1.18]$} \\
\hline \multirow[t]{2}{*}{$A A *$ Square of vacancy rate in the neighborhood } & -1.4698 & & & & & -1.3510 \\
\hline & {$[-0.67]$} & & & & & {$[-0.63]$} \\
\hline \multirow[t]{2}{*}{ Bedrooms } & -0.0133 & -0.0117 & -0.0109 & -0.0133 & -0.0119 & -0.0138 \\
\hline & {$[-1.42]$} & {$[-1.25]$} & {$[-1.17]$} & {$[-1.43]$} & {$[-1.27]$} & {$[-1.48]$} \\
\hline \multirow[t]{2}{*}{ Bathrooms } & -0.0022 & -0.0025 & -0.0013 & -0.0029 & -0.0013 & -0.0034 \\
\hline & {$[-0.22]$} & {$[-0.25]$} & {$[-0.13]$} & {$[-0.29]$} & {$[-0.13]$} & {$[-0.34]$} \\
\hline \multirow[t]{2}{*}{ Single family } & 0.0301 & $0.0421 *$ & $0.0424 *$ & 0.0286 & $0.0423^{*}$ & 0.0357 \\
\hline & [1.28] & {$[1.83]$} & {$[1.84]$} & [1.22] & [1.83] & {$[1.54]$} \\
\hline \multirow[t]{2}{*}{ Apartment } & $-0.0605 * * *$ & $-0.0647^{* * *}$ & $-0.0625 * * *$ & $-0.0624^{* * *}$ & $-0.0635 * * *$ & $-0.0663 * * *$ \\
\hline & {$[-3.29]$} & {$[-3.53]$} & {$[-3.42]$} & {$[-3.40]$} & {$[-3.47]$} & {$[-3.62]$} \\
\hline \multirow[t]{2}{*}{ Percentage college educated in neighborhood } & -0.0651 & -0.0223 & $-0.1088^{*}$ & 0.0085 & -0.0125 & -0.0343 \\
\hline & {$[-1.01]$} & {$[-0.43]$} & {$[-1.85]$} & {$[0.16]$} & {$[-0.22]$} & {$[-0.65]$} \\
\hline \multirow[t]{2}{*}{ Constant } & $0.4039 * * *$ & $0.6375^{* * *}$ & $0.4465^{* * *}$ & $0.6124 * * *$ & $0.5644 * * *$ & $0.6927 * * *$ \\
\hline & {$[4.94]$} & {$[22.81]$} & [7.93] & [19.02] & {$[10.66]$} & [19.99] \\
\hline Observations & 4042 & 4060 & 4058 & 4050 & 4060 & 4052 \\
\hline R-squared & 0.021 & 0.009 & 0.015 & 0.012 & 0.011 & 0.012 \\
\hline F Statistic & 3.955 & 6.160 & 6.258 & 4.769 & 4.709 & 4.864 \\
\hline
\end{tabular}

Notes: The dependent variable is a binary response, where unity implies an email response received. Neighborhood is defined as a census tract. Distance is the straight line distance in number of miles to the tallest building in the city. Median rent is at the city level by number of bedrooms; percentage of median rent is the simple ratio of reported rent to the median rent. P-values reported in brackets. ${ }^{* * *}, * *$, and ${ }^{*}$ denote significance at the $1 \%, 5 \%$, and $10 \%$ level respectively. 
The parametric results show strong support for the local polynomial smoothing estimation strategy. The direction and magnitude of the results buttress the non-parametric figures. For example, the percentage of white residents in the neighborhood has a positive and strongly significant impact on the probability of a response controlling for race and the interaction of race and white residence percentage. This shows the discrimination rate against African Americans is much higher as the percentage of white residents in the neighborhood increases (from zero to one). The square of the percent of white residents shows the effect of additional white residents falls for neighborhoods that are more than $50 \%$ white. This result mirrors the finding in Fig. 1, while controlling for other covariates that may affect landlord response.

The remaining parametric results also follow the nonparametric findings; however, some are not quite as statistically precise (although most remain statistically meaningful at the ten percent level). Higher rents lead to higher rates of discrimination against African Americans but at a decreasing rate around the critical value of 1.5 times the median rent. Likewise, very low or high vacancy rates lead to increases in the discrimination rate against African Americans around the critical value of $15 \%$. These patterns are similar to the nonparametric figures. The distance measure does not show statistical significance in any specification but the sign and magnitude are congruent with the nonparametric results.

\section{Conclusion}

We use a non-parametric estimation strategy to examine racial discrimination across neighborhood and housing unit characteristics. We examine how discrimination rates fluctuate within the distribution of racial composition, distance to city center, affordability, and vacancy rates. African American home-seekers are discriminated against at a higher rate than whites in neighborhoods that are racially mixed. They also face larger discrimination rates in areas with rents near or above the median rent for the city, as well as in areas with low or very high vacancy rates. Higher discrimination rates against African Americans are also observed in neighborhoods that are located very close to the center of the city or in the first ring of suburbs.

While it is extremely difficult to determine the exact cause of discrimination, the results do suggest that landlord taste is not the central cause of discrimination rates against home-seekers. In general, the perceived preference or current/future customer prejudice cause is much more plausible. Both of these hypotheses of discrimination are in line with statistical discrimination. While still illegal, the results suggest it is the landlords' intent to maximize profits by treating the marginal home-seeker like a perceived typical group member.

This study provides potential hot-spots for discrimination such as neighborhoods in the 'tipping' range, with low or very high vacancy rates, and with rents that are near or above the median rent for the city. This knowledge of where discrimination occurs is helpful for targeting future enforcement activities or for informing the choice of locations for public sessions on how to spot and report discriminatory behavior. We should note, however, that it is possible that a different sample of cities would produce different results, even if those cities have similar demographic and economic characteristics as our sample. It is possible that other factors about metropolitan areas such as segregation, commuting patterns, immigration, or local public services would play an important role that we do not capture in our data.

Our work does suggest that studies of discrimination should consider taking into account the types of neighborhoods in the sample selection process, as oversampling from certain neighborhoods may be consistent with finding above or below average discrimination rates. The literature and enforcement of Fair Housing Laws should also consider how access to specific types of neighborhoods may have a differential impact on housing outcomes than a general level of discrimination. 


\section{Acknowledgments}

The authors thank Bentley Coffey, participants at the Discrimination and Economic Outcomes session at the Western Economic Association International 85th annual meeting, and participants at the Texas Christian University Economics Department seminar series. We also thank Dan McMillen and two anonymous referees for helpful suggestions on improving the original manuscript.

\section{Appendix A. Robustness of estimates to bandwidth choice}

The choice of bandwidth may be the most commonly criticized parameter selection for local smoothing techniques. We test how sensitive our primary results are to changing the rule of thumb bandwidth in the local polynomial regression. We examine how choosing a smaller (one-half the size) and larger (twice the size) bandwidth changes our results.

Fig. A1 shows the discrimination rate across the percent of white residents' distribution using half and double the rule-of-thumb bandwidth, respectively. As Fig. A1 shows, the results are quite similar to the results for the standard rule of thumb bandwidth. Mixed neighborhoods still retain the higher discrimination rate differences with lower discrimination rates against African Americans in the largely majority neighborhood and the largely minority neighborhoods. Similarly, Fig. A2 illustrates the discrimination rates with half and double the rule-ofthumb bandwidth, against African American and white home-seekers along the distance to the city center distribution. Again the choice of bandwidth does not seem to affect the pattern that we observe.
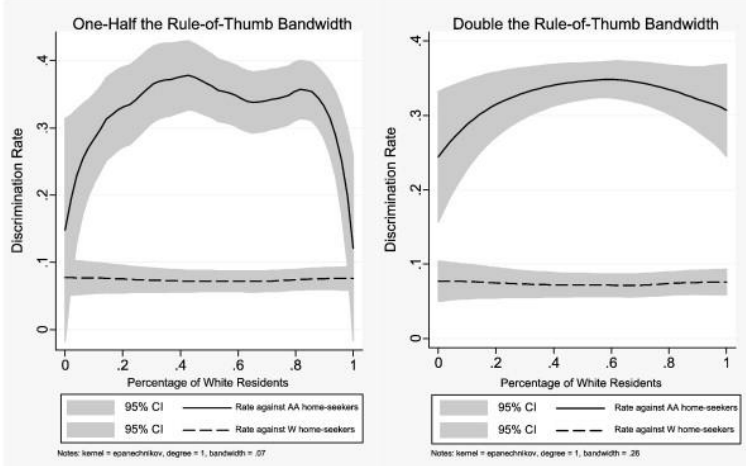

Fig. A1. Local linear smoothing by percentage of white residents robustness checks.

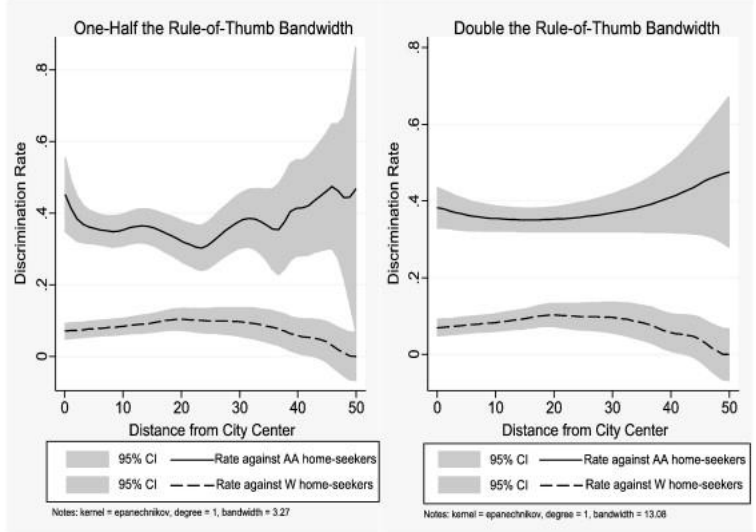

Fig. A2. Local linear smoothing by distance from city center robustness checks.

Fig. A3, Fig. A4 show the bandwidth robustness checks across the rent ratio and vacancy rate distribution. We find that the bandwidth choice does not change the distribution of discrimination substantially across any of these attributes. We also check the robustness of the results with the degree of polynomial and the kernel 
function choice for the local smoothing estimation. The choice of these parameters does not significantly alter the main conclusions described above.
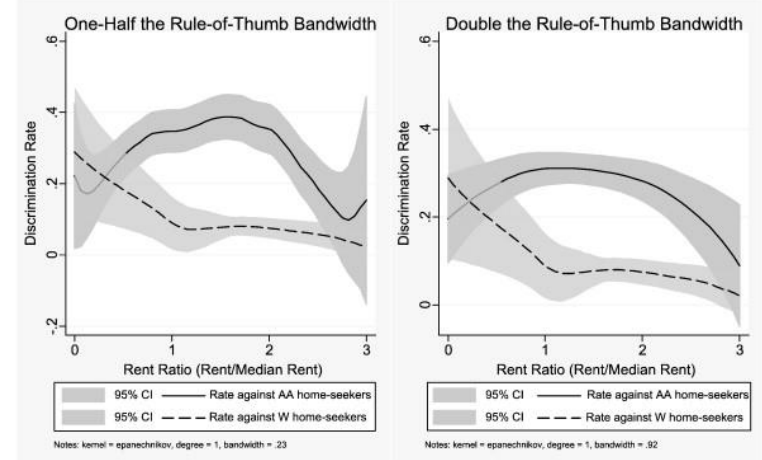

Fig. A3. Local linear smoothing by rent ratio robustness checks.
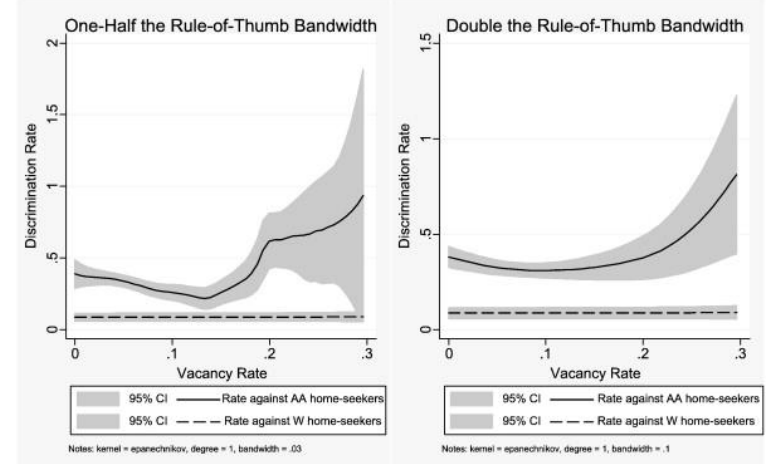

Fig. A4. Local linear smoothing by vacancy rates robustness checks.

\section{References}

Ahmed and Hammarstedt, 2008. Ali M. Ahmed, Mats Hammarstedt. Discrimination in the rental housing market: a field experiment on the internet. J. Urban Econ., 64 (2) (2008), pp. 362-372

Ahmed and Hammarstedt, 2009. Ali M. Ahmed, Mats Hammarstedt. Detecting discrimination against homosexuals: evidence from a field experiment on the internet. Economica, 76 (2009), pp. 588-597

Ahmed et al., 2008. Ali M. Ahmed, Lina Andersson, Mats Hammarstedt. Are lesbians discriminated against in the rental housing market? Evidence from a correspondence testing experiment. J. Hous. Econ., 17 (3) (2008), pp. 234-238

Ahmed et al., 2010. Ali M. Ahmed, Lina Andersson, Mats Hammarstedt. Can discrimination in the housing market be reduced by increasing the information about the applicants? Land Econ., 86 (1) (2010), pp. 79-90

Alesina et al., 1999. Alberto Alesina, Reza Baqir, William Easterly. Public goods and ethnic divisions. Q. J. Econ., 114 (4) (1999), pp. 1243-1284

Bertrand and Sendhil, 2004. Marianne Bertrand, Sendhil Mullainathan. Are Emily and Greg More Employable Than Lakisha and Jamal? A Field Experiment on Labor Market Discrimination. Am. Econ. Rev., 94 (4) (2004), pp. 991-1013

Bosch et al., 2010. Mariano Bosch, Angeles Carnero, Lidia Farre. Information and discrimination in the rental housing market: evidence from a field experiment. Reg. Sci. Urban Econ., 40 (1) (2010), pp. 11-19

Card et al., 2008. David Card, Alexandre Mas, Jesse Rothstein. Tipping and the dynamics of Segregation. Q. J. Econ., 123 (1) (2008), pp. 177-218

Carpusor and Loges, 2006. Adrian G. Carpusor, William E. Loges. Rental discrimination and ethnicity in names. J. Appl. Soc. Psychol., 36 (4) (2006), pp. 934-952 
Choi et al., 2005. Seok Joon Choi, Jan Ondrich, John Yinger. Do rental agents discriminate against minority customers? Evidence from the 2000 housing discrimination study. J. Hous. Econ., 14 (1) (2005), pp. 1-26

Cleveland, 1979. William S. Cleveland. Robust locally weighted regression and smoothing scatterplots. J. Am. Stat. Assoc., 74 (1979), pp. 829-836

Cleveland and Devlin, 1988. William S. Cleveland, Susan J. Devlin. Locally weighted regression: an approach to regression analysis by local fitting. J. Am. Stat. Assoc., 83 (1988), pp. 596-610

DiNardo and Tobias, 2001. John DiNardo, Justin L. Tobias. Nonparametric density and regression estimation. J. Econ. Perspect., 15 (4) (2001), pp. 11-28

Ewans et al., forthcoming. Michael Ewans, Bryan Tomlin, Liang Choon Wang. Statistical discrimination or prejudice? A large sample field experiment. Rev. Econ. Stat. (2013) (forthcoming)

Hanson and Hawley, 2011. Andrew Hanson, Zackary Hawley. Do landlords discriminate in the rental housing market? Evidence from an internet field experiment in US cities. J. Urban Econ., 70 (2-3) (2011), pp. 99-114

Hanson et al., 2011. Andrew Hanson, Zackary Hawley, Aryn Taylor. Subtle discrimination in the rental housing market: evidence from e-mail correspondence with landlords. J. Hous. Econ., 20 (2011), pp. 276-284

Heckman, 1998. James J. Heckman. Detecting discrimination. J. Econ. Perspect., 12 (2) (1998), pp. 101-116

Heckman and Siegelman, 1993. James J. Heckman, Peter Siegelman. The urban institute audit studies: their methods and findings. M. Fix, R. Struyk (Eds.), Clear and Convincing Evidence: Measurement of Discrimination in America (1993), pp. 187-258 (Chapter 5)

McMillen, 1996. Daniel P. McMillen. One hundred fifty years of land values in Chicago: a nonparametric approach. J. Urban Econ., 40 (1) (1996), pp. 100-124

McMillen and Redfearn, 2010. Daniel P. McMillen, Christian L. Redfearn. Estimation and hypothesis testing for nonparametric hedonic house price functions. J. Reg. Sci., 50 (3) (2010), pp. 712-733

Meese and Wallace, 1991. Richard Meese, Nancy Wallace. Nonparametric estimation of dynamic hedonic price models and the construction of residential housing price indices. Real Estate Econ., 19 (3) (1991), pp. 308-332

Ondrich et al., 1998. J. Ondrich, Alex Stricker, John Yinger. Do real estate brokers choose to discriminate? Evidence from the 1989 housing discrimination study. South. Econ. J., 64 (4) (1998), pp. 880-901

Ondrich et al., 1999. Jan Ondrich, Alex Stricker, John Yinger. Do landlords discriminate? The incidence and causes of racial discrimination in rental housing markets. J. Hous. Econ., 8 (3) (1999), pp. 185-204

Ondrich et al., 2000. Jan Ondrich, Steven L. Ross, John Yinger. How common is housing discrimination? Improving on traditional measures. J. Urban Econ., 47 (3) (2000), pp. 470-500

Ondrich et al., 2003. Jan Ondrich, Steven L. Ross, John Yinger. Now you see it, now you don't: why do real estate agents withhold houses from black customers? Rev. Econ. Stat., 85 (4) (2003), pp. 854-873, Page, 1995

Marianne Page. Racial and ethnic discrimination in urban housing markets: evidence from a recent audit study. J. Urban Econ., 38 (2) (1995), pp. 183-206

Phelps, 1972. Edmund Phelps. The statistical theory of racism and sexism. Am. Econ. Rev., 62 (4) (1972), pp. 659-661

Roychoudhury and Goodman, 1992. Canopy Roychoudhury, Allen C. Goodman. An ordered probit model for estimating racial discrimination through fair housing audits. J. Hous. Econ., 2 (4) (1992), pp. 358-373

Yinger, 1986. John Yinger. Measuring racial discrimination with fair housing audits: caught in the act. Am. Econ. Rev., 76 (5) (1986), pp. 881-893

Yinger, 1991. John Yinger. Acts of discrimination: evidence from the 1989 housing discrimination study. J. Hous. Econ., 1 (4) (1991), pp. 318-346

Zhao, 2005. Bo Zhao. Does the number of houses a broker shows depend on a homeseeker's race? J. Urban Econ., 57 (1) (2005), pp. 128-147

Zhao et al., 2006. Bo Zhao, Jan Ondrich, John Yinger. Why do real estate brokers continue to discriminate? Evidence from the 2000 housing discrimination study. J. Urban Econ., 59 (3) (2006), pp. 394-419 
${ }^{1}$ Tel.: + 14142885822.

${ }^{2}$ State-level Fair Housing Assistance Programs (FHAP) also handle discrimination complaints. These programs receive an additional 3000-4000 complaints annually. More of these complaints (7-8\%) end up in a charge of discrimination, but fewer are referred to the Department of Justice for enforcement.

${ }^{3}$ The DOJ recently settled with Bank of America for $\$ 335$ million in response to allegations that it's Countrywide Financial subsidiary practiced discrimination against African American and Hispanic borrowers by charging them higher fees and steering them into subprime mortgages (New York Times, "Country Wide Will Settle Bias Lawsuit", December 21, 2011).

${ }^{4}$ Three decades of academic work confirms that racial discrimination exists in housing markets. See Yinger (1986) for a classic example, and Hanson and Hawley (2011) for a recent example with citations to other newer studies.

${ }^{5}$ Experimental studies of racial discrimination have become the standard in separately identifying racial discrimination from other confounding factors. Other studies that use observational data on home prices (sales, self-reported, or assessed) suffer from bias caused by correlation between unobserved factors at the unit, person, and neighborhood level with outcomes of interest and race. While we see value in these studies for their ability to examine important outcomes, we question the magnitudes associated with the level of discrimination they find.

${ }^{6}$ Yinger puts these in the context of discrimination by real estate agents, but the concepts apply equally well to landlords of rental properties, which we examine here.

${ }^{7}$ For details of the original experiment see Hanson and Hawley (2011).

${ }^{8}$ The sample size is also limited by ArcGIS software not recognizing some addresses information, and by some landlords offering incomplete address information.

${ }^{9}$ The median rent data come from HUD. The ACS provides a self-reported gross rent available at the county level for 2010. Using either data produces the same result.

${ }^{10}$ The vacancy data come from Census. The ACS provides the number of for rent properties and the number of vacant for rent properties. The vacancy rate is a simple ratio of these two measures.

${ }^{11} \mathrm{An}$ urbanized area is defined by the Census Bureau as an area with 50,000 or more people and a densely settled core of census tracts or blocks along with adjacent territory with lower population density.

${ }^{12}$ The Ipoly statistical package in STATA 12 provides a "rule of thumb" method for bandwidth choice. We follow this choice as a starting point and provide robustness checks for this choice.

${ }^{13}$ We use the Epanechnikov kernel which is standard and applies increased weights to the observations as the distance from the point of interest falls to zero.

${ }^{14}$ We picked examples that were representative. The Atlanta sub-case is similar to Dallas and Houston. The Boston sub-case resembles Seattle and New York. The Chicago sub-case is comparable to San Francisco and Los Angeles.

${ }^{15}$ Even though the confidence intervals begin to expand at around $20 \%$ white residents, the predicted values are still relatively flat. This is due to the relatively small sample size in those neighborhood types for Boston. 16

These locations are representative of different patterns for the cities in our data. Atlanta is similar to Chicago, Seattle, and San Francisco, where Boston is aligned with District of Columbia, Los Angeles, New York, Dallas and Houston.

${ }^{17}$ In Atlanta, distance interacts with racial composition of neighborhoods. A basic description of the city is that there is an inner ring of African American majority neighborhoods surrounded by the heavily mixed urban area. Further out is a ring of more heavily African American populated suburbs encompassed by a ring of white populated neighborhoods. 